\title{
An integrative approach of the marketing research and benchmarking
}

\author{
Gina-Maria Moraru, ${ }^{1, *}$ \\ ${ }^{1}$ Lucian Blaga University of Sibiu, Engineering Faculty, Industrial Engineering and Management \\ Department, 4 Emil Cioran St, 550025 Sibiu, Romania
}

\begin{abstract}
The accuracy of the manager's actions in a firm depends, among other things, on the accuracy of his/her information about all processes. At this issue, developing a marketing research is essential, because it provides information that represents the current situation in organization and on the market. Although specialists devote the marketing research exclusively to the organizational marketing function, practice has shown that it can be used in any other function of the company: production, finance, human resources, research and development. Firstly, the paper presents the opportunities to use the marketing research as a management tool in various stages of creative thinking. Secondly, based on a study made from secondary sources of economic literature, the paper draws a parallel between marketing research and benchmarking. Finally, the paper shows that creative benchmarking closes the management marketing - creativity circle for the benefit of the organization and community.
\end{abstract}

\section{Introduction}

The accuracy of the manager's actions in a firm depends, among other things, on the accuracy of his/her information about all processes. At this issue, developing a marketing research is essential, because it provides information that represents the current situation in organization and on the market. Therefore, we consider that marketing research is an efficient tool in the study of the external environment of the company, but also in the study of its internal environment. There are many organizations that have implemented an internal marketing plan, in order to educate, stimulate and lead the workforce to higher levels of performance [1]. Implementing the internal customer concept stimulates the employees to encourage the customer to buy again the products or services of the company [2]. Internal customer satisfaction helps the organization to achieve sustainable competitive advantage over other firms [3].

Although specialists devote the marketing research exclusively to the organizational marketing function, practice has shown that it can be used in any other function of the company: production, finance, human resources, research and development [4].

${ }^{*}$ Corresponding author: gina.moraru@ulbsibiu.ro 


\section{Marketing research and creative thinking}

Many companies in Romania and around the world comply step by step with procedures of different types of marketing research when they:

- Are looking for new ideas for products among stakeholders (research and development).

- Are studying employees' behavior, perception or attitudes towards certain measures of change (human resources).

- Examine possibilities offered by the labor market, to employ staff (human resources).

- Are following the reorganization of production based on modern criteria (the organizational production function).

- Seek to detect all unprofitable activities which should be outsourced (finance).

We will demonstrate how marketing research can support the development of the newest resource of the company: the creativity.

Tony Proctor presents several of the theories of creative thinking [5]. We chose two of the most representative theories, which can use various types of marketing research as management instruments. We sketched in Figure 1 several white ellipses representing the Donald G. Marquis theory of creativity (1969) and four rectangles with Arabic numbers representing the theory of Graham Wallas (1926).

Marketing research types
usable in different stages of
the creative thinking

STAGES OF THE

CREATIVE

THINKING (1 - 4)

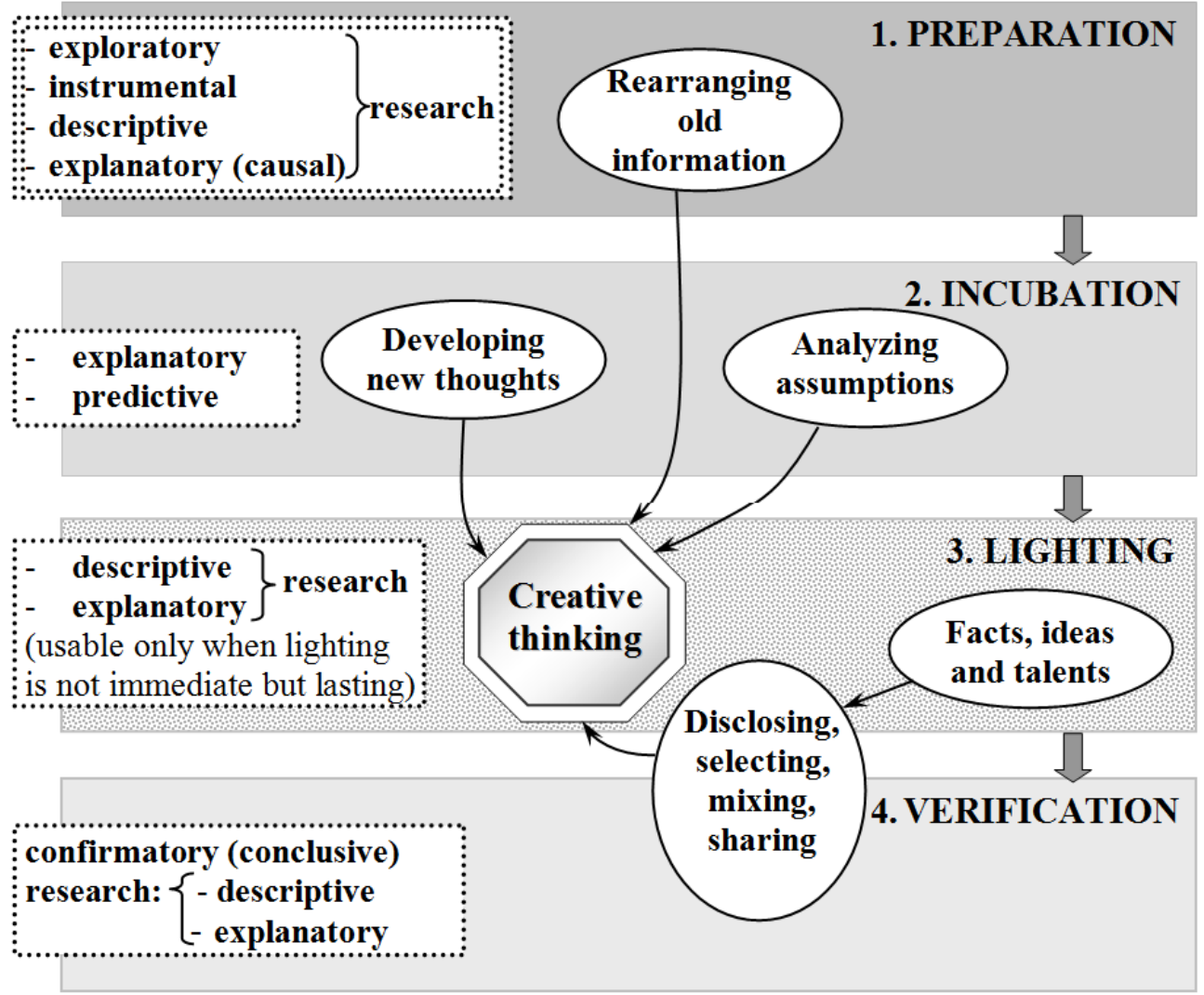

Fig. 1. Marketing research as a management tool in stimulating the creative thinking [4] 
We suggest in the left side of Figure 1 the possibility of using different types of marketing research in different stages of the creative thinking. We refer here to the human creative thinking, to the expert system (computer) creative thinking, or to the thinking of a group of specialists aided by a computer system, too.

\section{A parallel between marketing research and benchmarking}

According to Philip Kotler, the marketing research is structured into four stages: defining the problem and research objectives, developing the research plan, implementing the plan (with phases of collection, processing and analysis of data/information), and the stage of interpretation and reporting of the results [6]. Placing these stages alongside those of benchmarking, we notice that marketing research shows some similarities with benchmarking (Fig. 2).

Benchmarking is the method/process that determines who is the best in a specified field, who set the standards and what these standards are. Many managers have detected benchmarking "as the main tool delivering improvements through various management systems" [7].

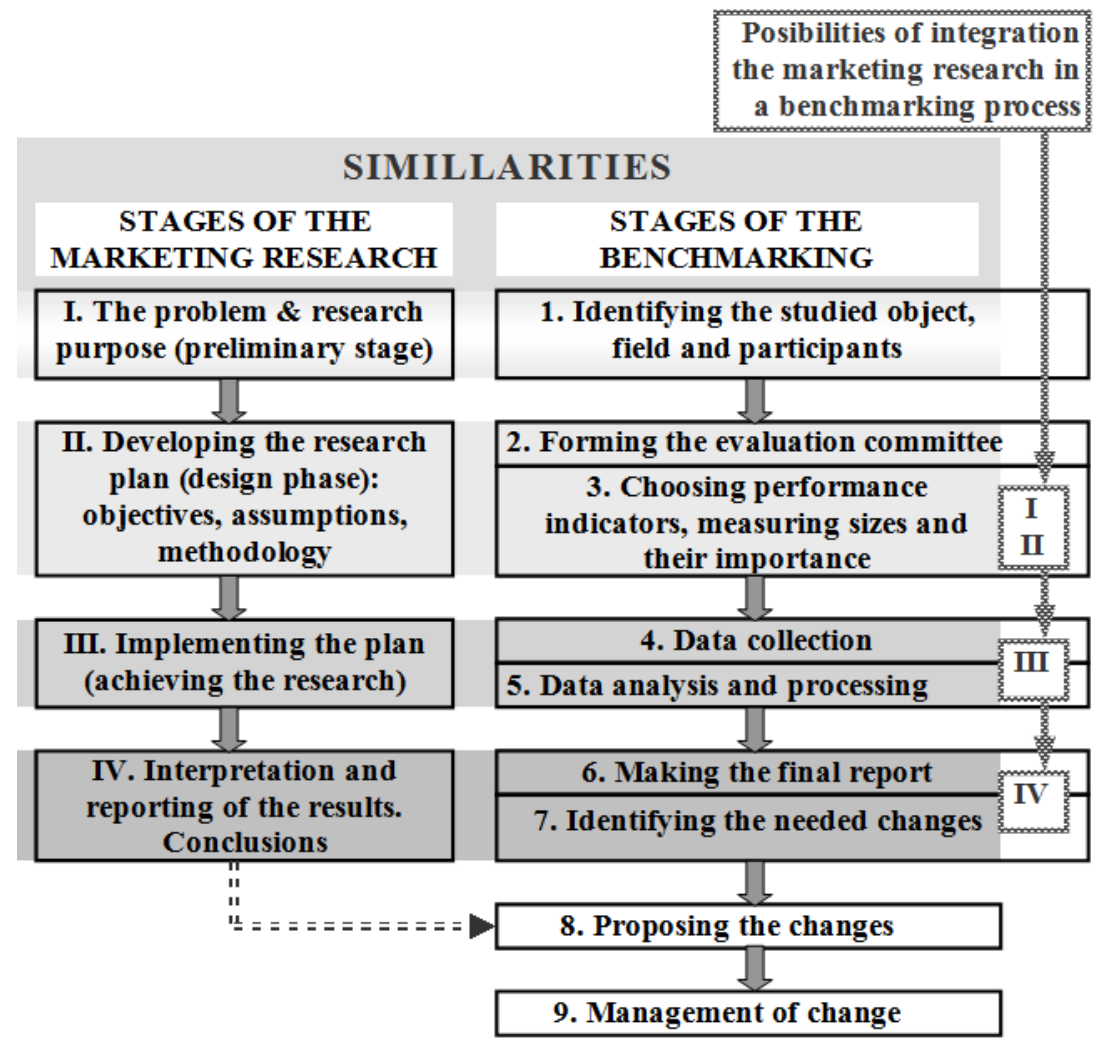

Fig. 2. Possibilities to use the marketing research in a modern benchmarking process

Even if marketing research and benchmarking are different processes, the similarities between their stages allow assimilation of marketing research - as extremely valuable management tool - in the process of benchmarking (Fig. 2).

The right side of Figure 2 has suggested a possible assimilation by Roman numerals indicating the place that you can handle benchmarking stages to ongoing research. 
The fact that there is an external and an internal benchmarking, but there also is an internal and an external marketing too, make it even easier the adoption of marketing research as an effective tool in benchmarking processes.

Besides effectiveness, marketing research is recognized as an instrument capable of operating in extremely complex environment to measure various organizational phenomena. There are four essential characteristics of data and values measured through a correctly carried out marketing research, characteristics that gives those data accuracy [8]. These characteristics offer many advantages to the use of marketing research in benchmarking. Thus, a benchmarking that use marketing research as a management tool, compared to a usual benchmarking process, will benefit a larger proportion from:

- The accuracy of the data/sizes with which the process is operated. Random errors of benchmarking decrease or are even canceled.

- The validity of the measurements made. In our opinion, the degree to which the measurement procedure does not generate a systematic or a random error increases.

- The generalization of the results of measurements of the entire population statistical samples. It greatly reduces the cost of benchmarking process if, for instance, not all employees will be surveyed a section, but only a representative sample.

- The sensitivity of the discovered input-output relationships. With the help of marketing research, the benchmarking reveals with a greater precision the factors that actually participate in determining the cause-effect reactions in the organization.

After studying the specialty literature ([9-13]), we proposed a summary of the most important advantage of the creative benchmarking (Fig. 3). Using the marketing research as an instrument, the creative benchmarking has become today a strategic method used more and more often at the national or global level in economy.

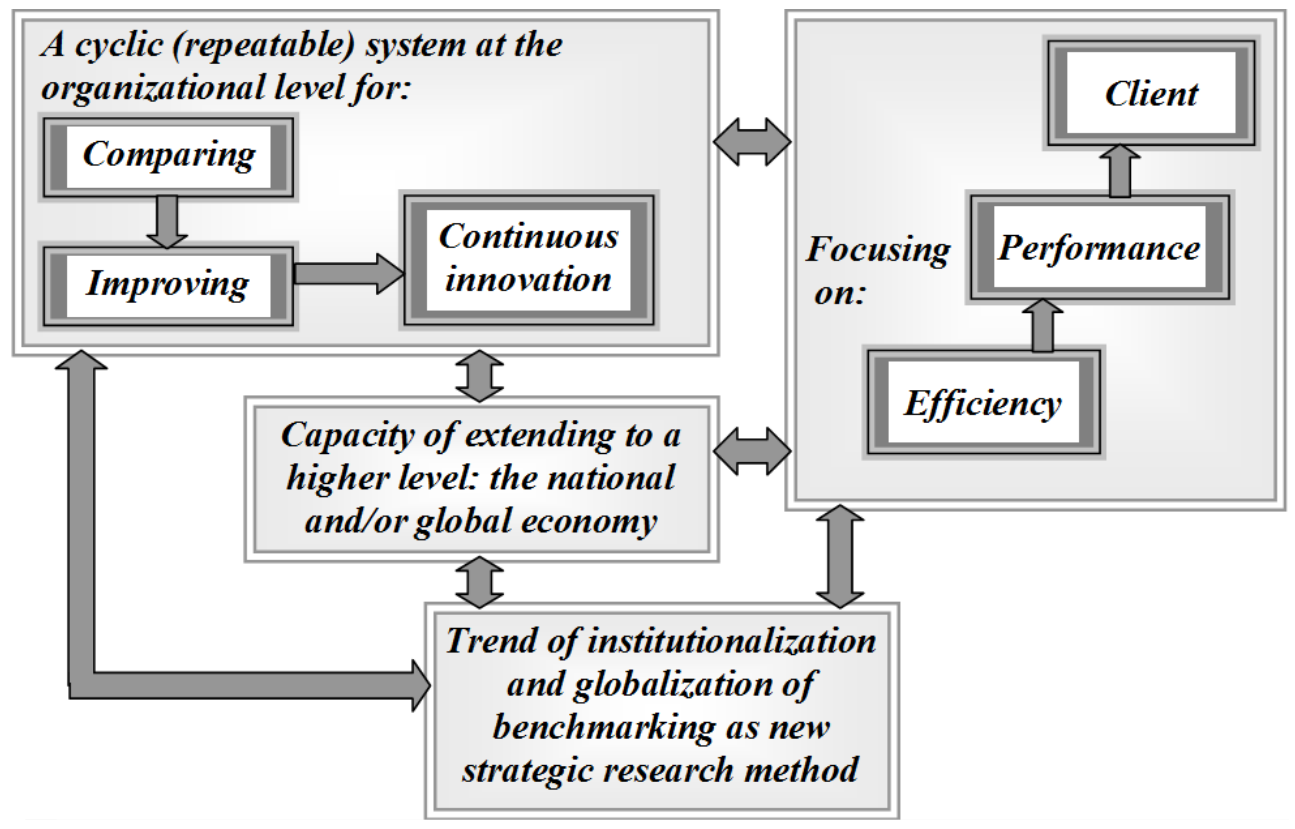

Fig. 3. A summary of the most important advantages of the modern creative benchmarking

A modern creative benchmarking has four essential characteristics: it is selective, has clear objectives, is focused on client and based on the organizational human values [4]. 


\section{Case-study}

One of the results of a larger research made in the Romanian academic environment on creativity management and modern benchmarking shows that $31.8 \%$ of the academics and $40 \%$ of the $\mathrm{PhD}$ students in management accept the need for a perfect balance between three of the factors that contribute to the value creation in the company: the creativity management, the marketing concept and the use of the modern management methodology, including the modern benchmarking [4]. These percents are the majority of respondents' opinions.

The study was made on 44 academics and $50 \mathrm{PhD}$ students in management and was based on questionnaires.

Some of the respondents suggested to an open question that an integrative approach of these three elements in company will help the manager to lead more efficiently the teamwork - sustaining other studies presented in the managerial literature [14] - and will sustain the organizational effort for achieving new performances.

$22.7 \%$ of the academics and $20 \%$ of the $\mathrm{PhD}$ students accorded more importance to the creativity management than to the other two analyzed factors, but they accepted anyway the necessity of integrating the three mentioned factors. $18.2 \%$ of the academics and $20 \%$ of the $\mathrm{PhD}$ students accorded more importance to the marketing concept, while the same percentages of respondents accorded more importance to the use of the modern management methodology, including the modern benchmarking. 9.1\% of the academics accorded more importance to an integrative approach of two from the three above mentioned factors [4].

The respondents' answers at many open questions have suggested the idea that all participants to a creative benchmarking process will find new solutions to improve their activities and processes. However, many respondents noticed many similarities between the marketing research and modern benchmarking, concerning their stages, deployment mode and impact on the organizations. In this context, the increase of efficiency and performance of the organizations that participate to a modern benchmarking process will have positive effect in their community.

\section{Conclusions}

This paper recommended the use of the marketing research as a management tool in various stages of creative thinking, in order to base the new ideas developed in an organization on real, accurate and actual information. The paper suggested some possibilities to use the marketing research in a modern benchmarking process, too.

The similarities between marketing research and benchmarking allow their integrated use in organization, in order to discover all important and actual information that can lead the firm to performance.

Moreover, the entire society has to win after the use of the new type of benchmarking at a national or global level (Fig. 3). Focusing on efficiency, performance and client, the creative benchmarking closes the management - marketing - creativity circle for the benefit of the organization and community.

This work was supported by the grant LBUS-IRG-2016-02, co-financed by the Lucian Blaga University of Sibiu, Romania. 


\section{References}

1. S. Mishra, Int. J. Bus. \& Mgmt. 5(1), 185-193 (2010)

2. G. Herrington, W. Lomax, Kingston Bus. School, Occasional Paper Series 34 (1999)

3. K.P.M. Byju, Global J. Mgmt. \& Bus. Studies, 3(5), 519-524 (Research India Pub., 2013)

4. G.M. Moraru, PhD Thesis: Creativity Management and Benchmarking Promoting Performance and Competitiveness in Modern Organizations, Lucian Blaga Univiversity of Sibiu (2011, unpublished)

5. T. Proctor, Elemente de creativitate managerial (Teora, Bucureşti, 2000)

6. Ph. Kotler, G. Armstrong, Principiile marketingului (Teora, 2000)

7. J. Moriarty, C. Smallman, Benchmarking Int. J. 16(4), 484-503 (Emerald, 2009)

8. I. Catoiu, Cercetari de marketing, 171-178 (Uranus, 2002)

9. J. Alexis, Metoda Taguchi in practica industriala. Planuri de experiente (Tehnica, 1999)

10. R.L. Ackoff, Systemic Practice \& Action Res. J. 6(6), 581 (1993)

11. O. Nicolescu, Management comparat (Ed. Ec., 1997)

12. O. Nicolescu, I. Verboncu, Management (Ed. Ec., 1996)

13. M.S. Attiany, J. Bus. Studies Quarterly, 5(4), 41-51 (2014)

14. D. Miricescu, Rev. Manag. \& Economic Eng. 14(1), 65-77 (2015) 